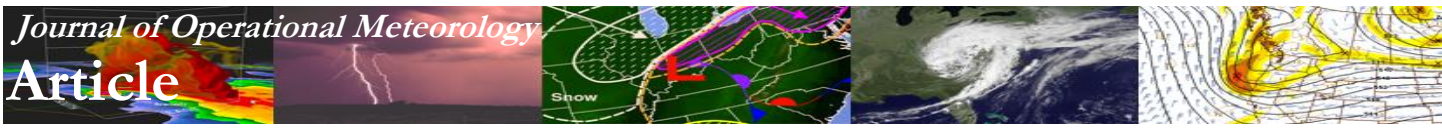

\title{
A Wet-Bulb Globe Temperature Validation Study using Standard Meteorological Inputs and Modeled Solar Irradiance
}

\author{
DAVID P. SAUTER \\ Army Research Laboratory, White Sands Missile Range, New Mexico
}

(Manuscript received 1 May 2013; review completed 18 October 2013)

\begin{abstract}
Heat-stress-related injuries and deaths are a serious concern to the military. A joint Army/Air Force publication (TB MED 507) provides heat stress guidance based on the wet-bulb globe temperature (WBGT), soldier work rate, and clothing level. In a military environment, however, accurate WBGT measurements or predictions (for planning purposes) may not be available or practical to obtain; thus, a physics-based model provides the WBGT value from standard meteorological inputs. Likewise, the surface solar irradiation value (required for the WBGT computation) is determined from a model as a function of cloud amount and type, surface albedo, geographic location, and date/time. The author performed an experimental study to determine the validity of using the two models for obtaining the WBGT. The WBGT and solar irradiation models, as well as the TB MED 507 guidance, have been hosted on an Android-based smartphone to provide heat stress guidance on a highly portable solution for the Army. One advantage of the current capability over WBGT instrumentation is its ability to be used as a planning tool via entry of forecast input parameter values into the algorithm.
\end{abstract}

\section{Introduction}

According to Carter et al. (2005) there is an annual average of over 200 United States soldier hospitalizations and two deaths due to heat stress injuries. In an attempt to mitigate these injuries, the Department of the Army and Air Force Headquarters (2003) Technical Bulletin Medical 507 (TB MED 507) provides guidance on work times and hourly water consumption (Table 1 and Table 2) as a function of the wet-bulb globe temperature (WBGT), soldier work rate, and clothing configuration. The WBGT (calculated in ${ }^{\circ} \mathrm{C}$ in this study) is defined as:

$W B G T=0.7 T_{w}+0.2 T_{g}+0.1 T_{a}$.

$T_{w}$ is the natural wet-bulb temperature and is measured by exposing a stationary thermometer bulb covered with a wetted wick (distilled water) to the sun and wind (unlike the psychrometric wet bulb in which the wetted wick is sheltered from the sun via enclosure in an aspirated radiation shield). It provides an indication of the effects of relative humidity (RH) on an individual. $T_{g}$ is the globe temperature that is obtained via exposure to the sun of a thermometer bulb within a 15.24-cm (6-in) hollow copper sphere painted flat black. It provides an indication of the radiant heat exposure from the sun on an individual. $T_{a}$ is the drybulb temperature (i.e., the ambient temperature) measured with a dry-bulb thermometer shielded from the direct rays of the sun.

Liljegren et al. (2008; hereafter L08) of Argonne National Laboratory (ANL) showed that, given accurate meteorological inputs (air temperature, wind speed, atmospheric pressure, $\mathrm{RH}$, and solar irradiance), $T_{w}$ and $T_{g}$ can be satisfactorily obtained from a model they developed based on fundamental principles of heat and mass transfer ( $T_{a}$ is measured directly). With the exception of the total solar irradiance parameter, the ANL WBGT model input parameters should be available for Army operations via standard meteorological instrumentation. The irradiance value, as opposed to being measured directly, is modeled as a function of date, time, 
Table 1. Fluid replacement and work/rest guidelines for warm-weather training conditions. This applies to an average-size and heat-

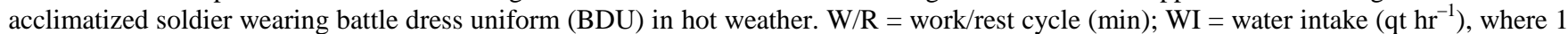
$\mathrm{qt}=946.3 \mathrm{~cm}^{3} ; \mathrm{NL}=$ no limit to work time per hour (up to 4 continuous hours). Adapted from Table 3-1 of the Department of the Army and Air Force Headquarters (2003).

\begin{tabular}{|c|c|c|c|c|c|c|c|}
\hline \multirow[b]{2}{*}{$\begin{array}{c}\text { Heat } \\
\text { Category }\end{array}$} & \multirow[b]{2}{*}{$\begin{array}{c}\text { WBGT }^{1,2} \\
\text { Index }\left({ }^{\circ} \mathrm{C}\right)\end{array}$} & \multicolumn{2}{|c|}{ Easy Work (250 watt) } & \multicolumn{2}{|c|}{ Moderate Work (425 watt) } & \multicolumn{2}{|c|}{ Hard Work (600 watt) } \\
\hline & & $\mathbf{W} / \mathbf{R}$ & WI & $\mathbf{W} / \mathbf{R}$ & WI & $\mathbf{W} / \mathbf{R}$ & WI \\
\hline 1 & $25.6-27.7$ & NL & $1 / 2$ & NL & $3 / 4$ & $40 / 20$ & $3 / 4$ \\
\hline 2 & $27.8-29.3$ & NL & $1 / 2$ & $50 / 10$ & $3 / 4$ & $30 / 30$ & 1 \\
\hline 3 & $29.4-31.0$ & NL & $3 / 4$ & $40 / 20$ & $3 / 4$ & $30 / 30$ & 1 \\
\hline 4 & $31.1-32.2$ & NL & $3 / 4$ & $30 / 30$ & $3 / 4$ & $20 / 40$ & 1 \\
\hline 5 & $>32.2$ & $50 / 10$ & 1 & $20 / 40$ & 1 & $10 / 50$ & 1 \\
\hline
\end{tabular}

Table 2. Same as Table 1 except for continuous work.

\begin{tabular}{|c|c|c|c|c|c|c|c|}
\hline \multirow[b]{2}{*}{$\begin{array}{c}\text { Heat } \\
\text { Category }\end{array}$} & \multirow[b]{2}{*}{$\begin{array}{c}\text { WBGT } \\
\text { Index }\left({ }^{\circ} \mathbf{C}\right)\end{array}$} & \multicolumn{2}{|c|}{ Easy Work $(250 \mathrm{~W})$} & \multicolumn{2}{|c|}{ Moderate Work (425 W) } & \multicolumn{2}{|c|}{ Hard Work $(600 \mathrm{~W})$} \\
\hline & & $\mathbf{W} / \mathbf{R}$ & WI & $\mathbf{W} / \mathbf{R}$ & WI & $\mathbf{W} / \mathbf{R}$ & WI \\
\hline 1 & $25.6-27.7$ & NL & $1 / 2$ & NL & $3 / 4$ & 70 & 1 \\
\hline 2 & $27.8-29.3$ & NL & $1 / 2$ & 150 & 1 & 65 & $11 / 4$ \\
\hline 3 & $29.4-31.0$ & NL & $3 / 4$ & 100 & 1 & 55 & $1 \frac{1 / 4}{4}$ \\
\hline 4 & $31.1-32.2$ & NL & $3 / 4$ & 80 & $11 / 4$ & 50 & $1 \frac{1 / 4}{4}$ \\
\hline 5 & $>32.2$ & 180 & 1 & 70 & $1 \frac{1 / 2}{2}$ & 45 & $1 \frac{1}{2}$ \\
\hline
\end{tabular}

geographic location, surface albedo, and cloud amount and type. It is computed via a three-layered atmosphere (for low, middle, and high clouds) and a ground surface model developed by Shapiro (1982; hereafter S82) - in which the layer transmission and reflection coefficients have been determined using cloud amount and type in conjunction with surface incident solar irradiance measurements from the NCDC $(1978,1979)$ dataset. This modeled value eliminates the need for solar radiation instrumentation as well as the associated regular maintenance required for accurate measurements. Lower-end pyranometers with digital displays are available for as little as $\$ 100$, but will only provide irradiation measurements that are typically accurate within $5 \%$. There will be additional errors due to temperature dependence $\left(\sim 0.1 \%{ }^{\circ} \mathrm{C}^{-1}\right.$ from the $25^{\circ} \mathrm{C}$ calibration), non-horizontal mounting of the sensor, and potentially a dirty sensor covering, among others. Although a WBGT instrument is available for Army use, accurate natural $T_{w}$ measurements require distilled water and a clean wick, neither of which may be readily available in a tactical environment. For this study, a handheld Kestrel weather meter (kestrel meters.com) was used to measure the $\mathrm{RH}$ (which is used for the $T_{w}$ computation) via a polymer capacitive sensor without the requirement for water. According to Kestrel documentation (www.nkhome.com/pdfs/Kestrel_specs.pdf), their weather meters provide an $\mathrm{RH}$ measurement that is accurate within $\pm 3 \%$ (calibration drift of $\pm 2 \%$ over two years; field recalibration available). A 3\% error in the RH measurement - under a typical heat stress scenario - may result in an uncertainty of $\sim 0.5^{\circ} \mathrm{C}$ in the computed WBGT value. This sensor was chosen because similar or identical Kestrel meters are used by the Air Force weather squadrons in their support of Army tactical operations (Fig. 1). Last, Kestrel has recently developed a handheld sensor (Kestrel model 4400 , also not dependent on distilled water) that will determine the WBGT within just over $2^{\circ} \mathrm{C}$ of a fullsized WBGT setup. A distinct and critical advantage that the methodology outlined in this paper has over (i) the Kestrel 4400, (ii) the Army instrumentation, and (iii) other WBGT instrumentation is the capability to readily compute a predictive WBGT value based on forecast meteorological conditions. This can provide invaluable guidance as a planning tool.

The L08 and S82 algorithms were coded in the Java programming language and hosted on an Android-based smartphone to allow a real-time computation of the WBGT. TB MED 507 guidance (Table 1 and Table 2) was incorporated into the application to provide an automated determination of the work-rest cycle, continuous work time, and water intake requirements as a function of the WBGT value, soldier work rate, and clothing configuration. Because 


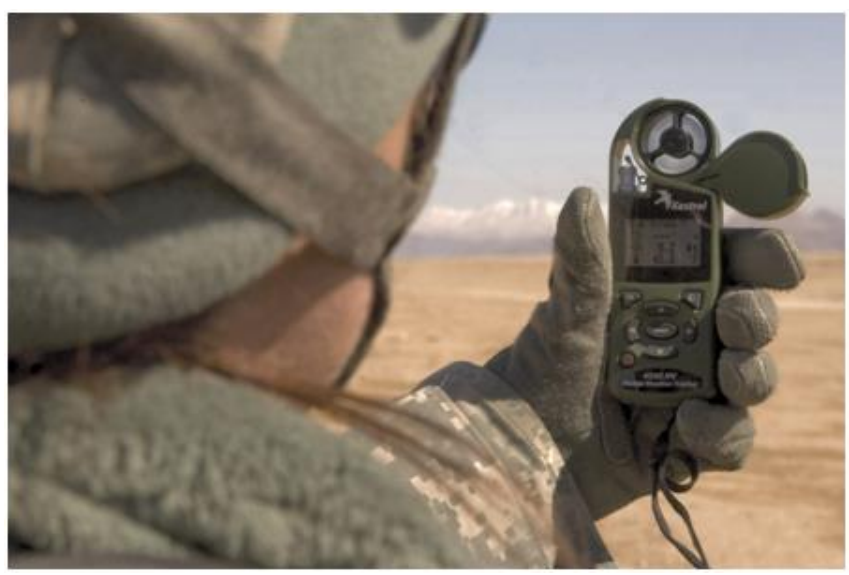

Figure 1. United States Army Sgt. Elizabeth Ellison, a helo landing zone control officer assigned to 2nd Stryker Cavalry Regiment, takes a wind reading prior to an Afghan C-27 aircraft training bundle-air delivery at a drop zone during the hands-on portion of a landing-zone safety officer class near Forward Operating Base Lagman in Zabul province, Afghanistan, 17 February 2011. Air Force and Army Service members were at the class with Romanian Land Forces to be certified to safely run the dirt landing strip and drop zone. The class was taught by Air Force instructors from Combined Joint Task Force 101. Photo courtesy of the United States Air Force. Click image for an external version; this applies to all figures hereafter.

this guidance is based on the WBGT, it is critical that an accurate WBGT value be obtained. As noted by L08, each heat category from Table 1 spans a range of $\sim 1.1-1.7^{\circ} \mathrm{C}$, so to correctly identify the category the WBGT model must be accurate to within $1^{\circ} \mathrm{C}$. Thus, a validation study of the ANL-based WBGT model (with solar irradiance modeled) as implemented on a mobile device was undertaken to determine the validity of providing heat stress guidance using only inputs readily available in a tactical environment. A summary of the mobile application and the WBGT validation experiment follows.

\section{a. Hot Environment Assessment Tool}

The Hot Environment Assessment Tool (HEAT) is an Android-based application that incorporates heat stress guidance found in Table 1 and Table 2. The following is a brief summary of the HEAT application; see Sauter (2012) for a more complete discussion. The first tabbed input screen (Fig. 2) allows entry of the site-related information that is required for the determination of the solar altitude, and subsequently, the clear-sky solar irradiance value. The default date and time entries are populated automatically from the values as set on the device. If the device incorporates a global-positioning-system capability, the default lati-

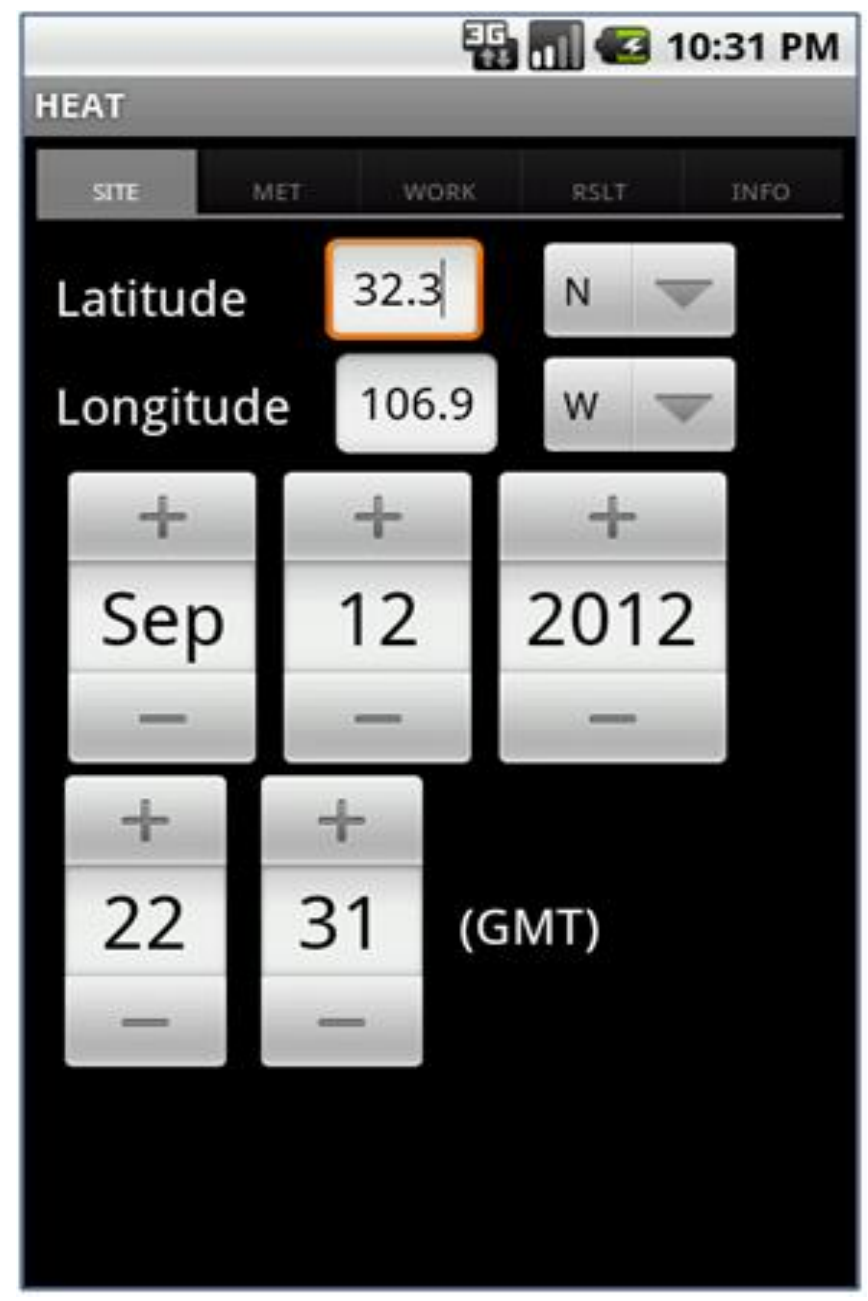

Figure 2. The HEAT "SITE" screen for entry of the observation site's location and date/time information.

tude and longitude values also could be assigned automatically.

Figure 3 shows the meteorological (MET) input screen that allows for either manual or automated (via a wireless connection to a Bluetooth-enabled weather sensor) entry of the required weather parameters. The cloud amount and type are manually entered from a visual observation. Representative photos of the various cloud types are available for assistance in selecting the proper cloud type (Fig. 4). Regarding use of the term "humid climate" in note 1 of Table 1 , since it is not defined meteorologically in the document, HEAT internally defines "humid" as a dewpoint value $>18.3^{\circ} \mathrm{C}\left(65^{\circ} \mathrm{F}\right)$. Because irradiance values (required for the $T_{g}$ and $T_{w}$ computations) can vary by $5 \%$ or more as a function of albedo, the MET input screen will be modified before release to allow a user entry for surface type that then will be used to internally 


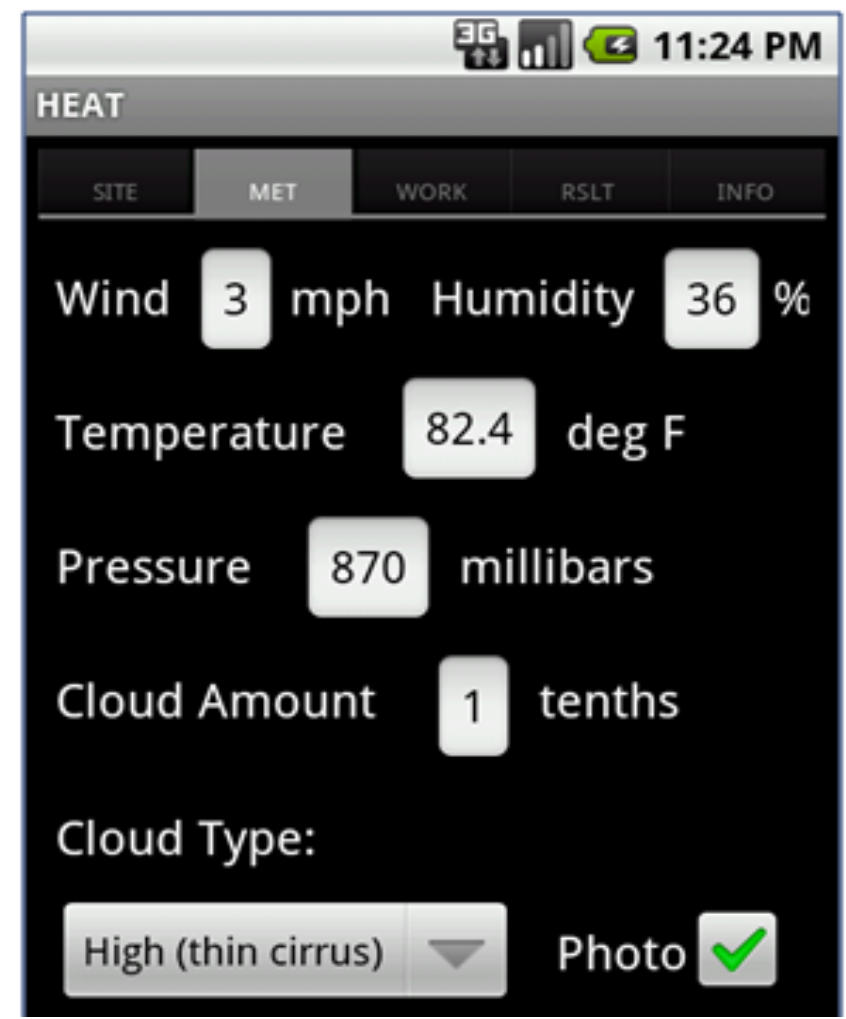

Figure 3. The HEAT "MET" screen for entry of the meteorological information.

assign an albedo (readily available from general meteorology and climatology texts).

The work screen (not shown) is for entry of the soldier workload and clothing configuration. Once all inputs are entered and the result tab is selected, the attenuated solar irradiance and WBGT values are computed. After any necessary internal adjustments to the WBGT per Table 1-notes to account for work rate, clothing configuration, and $\mathrm{RH}$ - the work and rest times and water consumption rate are determined for a 60-min work-rest cycle and a continuous work period and displayed (Fig. 5). In addition, the WBGT value is displayed.

\section{Data and methods}

\section{a. Meteorological measurements}

The ground truth WBGT value was obtained from a $3 \mathrm{M}^{\mathrm{TM}}$ QUESTemp 32 WBGT instrument (Fig. 6, also see www.heatstress.nl/en/product/2/3m-ques temp-32-34-36.html) mounted on a 0.91-m (3-ft) tripod. As seen in Fig. 6, this instrumentation has separate $T_{g}$ (top left), $T_{w}$ (top center), and $T_{a}$ (top right) sensors. A digital display indicates the individual $T_{g}$, $T_{w}$, and $T_{a}$ values, in addition to the RH (measured via

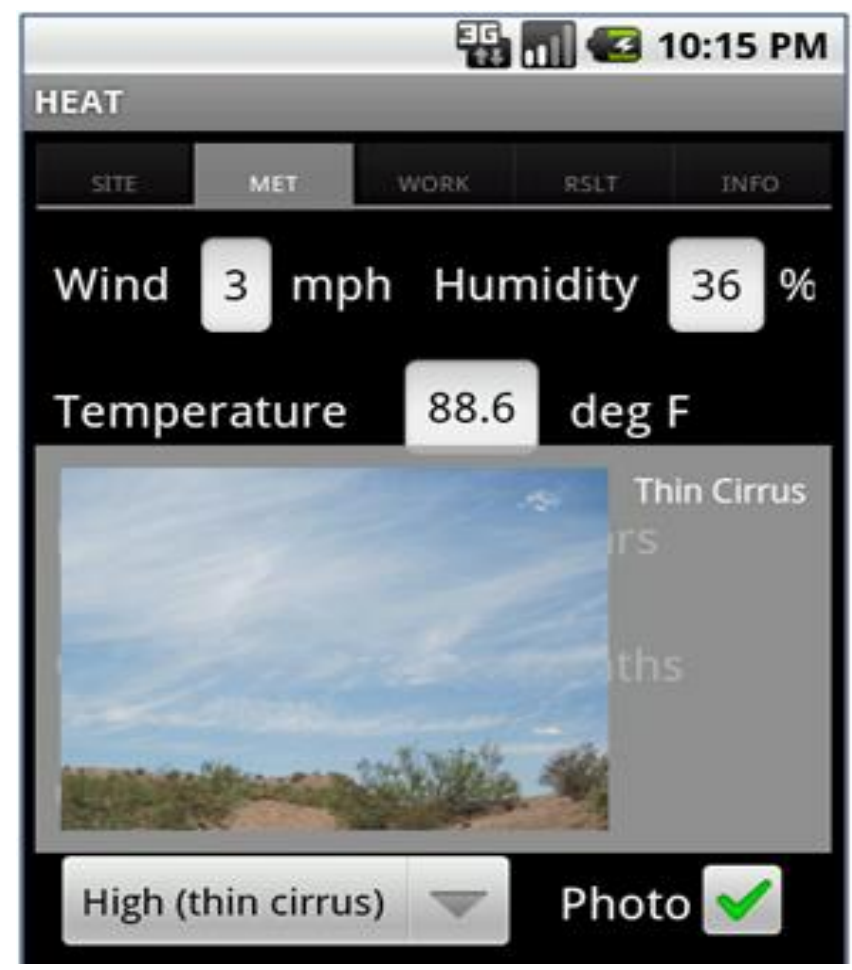

Figure 4. The HEAT "MET" tab displaying the thin cirrus cloud type photo.

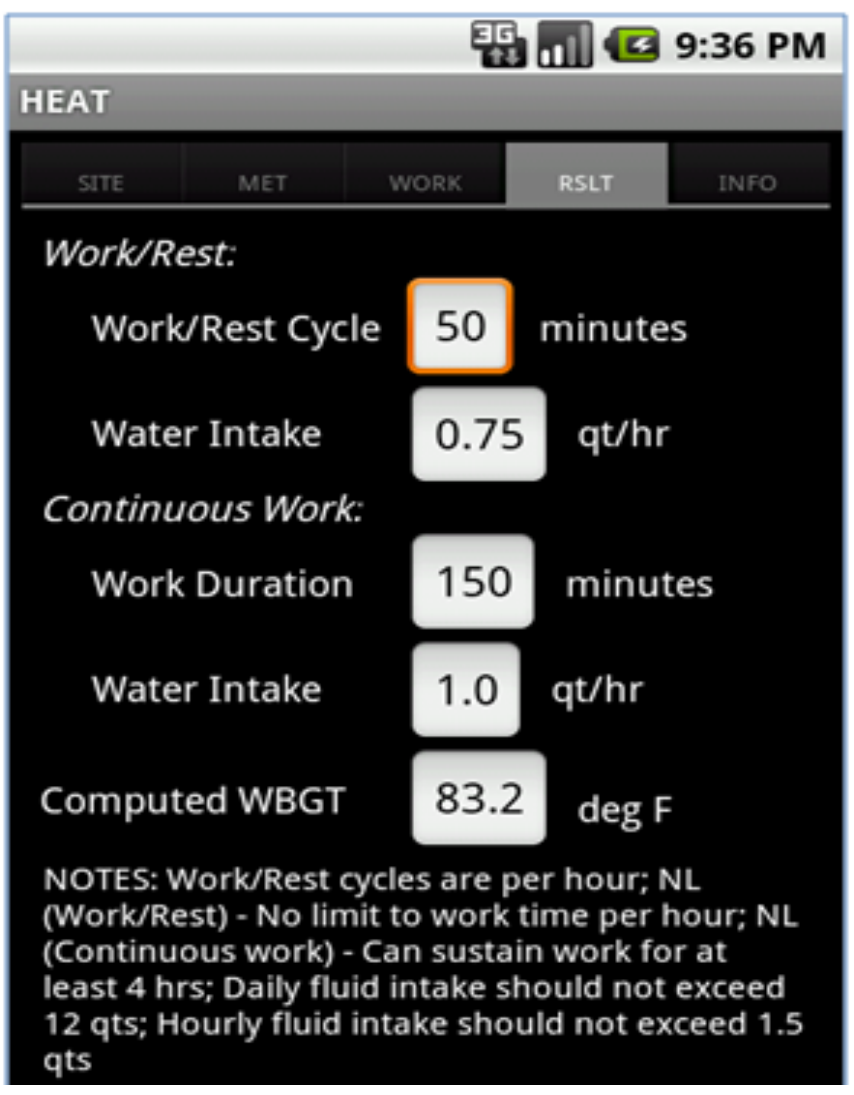

Figure 5. The HEAT "RSLT" tab displaying the heat stress guidance results. 


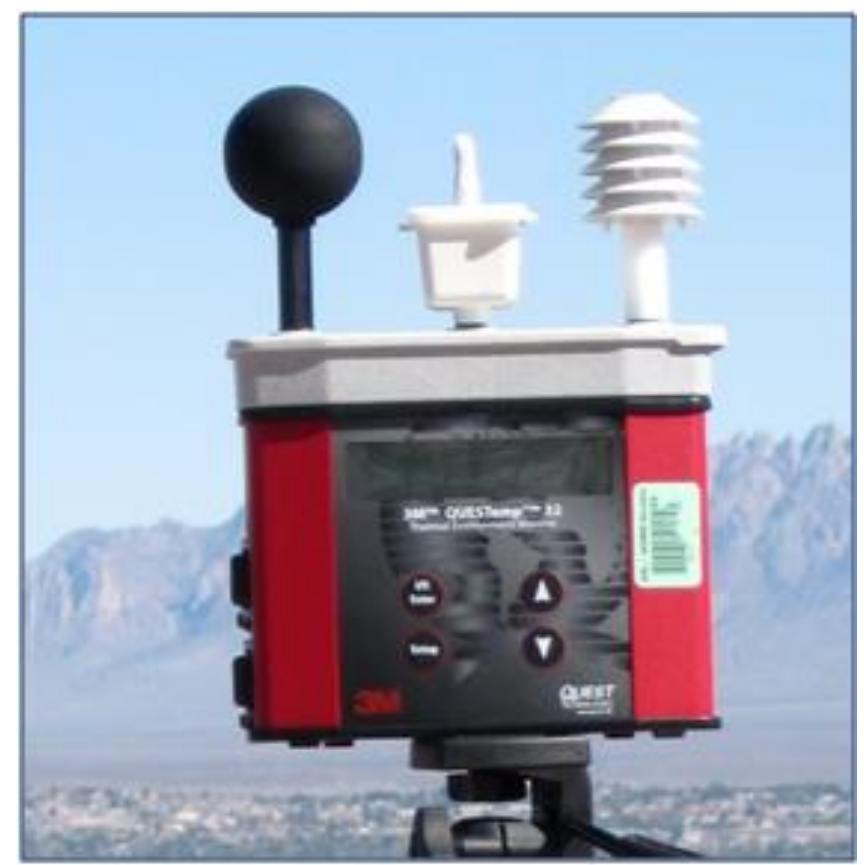

Figure 6. $3 \mathrm{M}^{\mathrm{TM}} \mathrm{QUESTemp}^{\mathrm{o}} 32 \mathrm{WBGT}$ instrumentation.

an internal sensor not visible in Fig. 6) and the calculated WBGT. According to the 3M Personal Safety Division (3M 2013), the QUESTemp ${ }^{\circ} 32$ temperature accuracy is $\pm 0.5^{\circ} \mathrm{C}$ between 0 and $120^{\circ} \mathrm{C}$ with an RH accuracy of $\pm 5 \%$ between 20 and $95 \%$ (non-condensing). Note that the black globe sensor is not a 15.24-cm (6-in) diameter sphere for which the WBGT is defined. The QUESTemp ${ }^{\circ} 32$ instrument uses a 5.08-cm (2-in) diameter globe for a faster response time and is correlated to match that of a 15.24-cm (6-in) globe. The digital display is updated once per second. In addition to the WBGT value, the instrument displays the $T_{w}$ and $T_{g}$ values. These were recorded for comparison with the modeled values. $T_{a}$ is displayed and was recorded for general comparison with the Kestrel $T_{a}$ value (see below).

Meteorological input values used by the HEAT application to compute the WBGT using the L08 and S82 methodologies were obtained from a Bluetoothenabled handheld Kestrel model 4500 weather meter (with a night vision screen). The Kestrel device was chosen because of its compact nature, durability, and current use in a tactical military environment. In addition to the RH details, the Kestrel meter measures (i) wind speed with an accuracy of the larger of $\pm 3 \%$ of the reading or least significant digit (0.36-39.78 m $\left.\mathrm{s}^{-1}\right)$; (ii) $T_{a}$ with an accuracy of $\pm 1.0^{\circ} \mathrm{C}$ ( -29.0 to $70.0^{\circ} \mathrm{C}$ ); and (iii) pressure with an accuracy of \pm 1.5 $\mathrm{hPa}\left(750-1100 \mathrm{hPa}\right.$ at $\left.25^{\circ} \mathrm{C}\right)$.
A convenient feature of the Kestrel weather meter is the ability to sample and store parameter values at a user-specified rate and duration. The user can start and stop the data sampling with the push of a single button. This feature was used to sample input values over a 30 -s period with samples taken every $2 \mathrm{~s}$, and then display the averaged values. The QUESTemp ${ }^{\circ} 32$ instrument does not have this capability, so average values were obtained via a visual inspection over the 30-s Kestrel sampling period and then manually recorded. In general, the QUESTemp 32 parameter values did not vary much over this period except under conditions of light and variable wind speeds or rapidly changing solar load (e.g., a cloud moving into or out of the view of the direct sun). Observations of this nature were limited in number (10 out of over 200 total). The 30 -s sampling period was chosen somewhat arbitrarily in an effort to mitigate the short-term fluctuations in the meteorological values. A longer duration sampling time may be more appropriate; however, the end user was kept in mind in determining a realistic time. As to not burden the end user, the HEAT application sampling and averaging of the Kestrel inputs is automated on the Android device itself. If a weather sensor with Bluetooth connectivity is not available for automated upload to the Android device, the user can manually enter the data.

There was generally good agreement between the parameter values ( $\mathrm{RH}$ and $T_{a}$ ) that were available on both the QUESTemp ${ }^{\circ} 32$ and Kestrel instruments. Over $90 \%$ of $T_{a}$ values were within $0.5^{\circ} \mathrm{C}$ for the two devices. An average RH difference of $\sim 3 \%$ was noted at low ambient humidities $(<30 \%)$, increasing to $\sim 7 \%$ for RH values at or above 30\%; Kestrel values tended to be lower. RH readings at the Las Cruces International Airport ( $\sim 7 \mathrm{~km}$ west-northwest of the WBGT validation site and at $\sim 100 \mathrm{~m}$ higher elevation) were observed intermittently during the study period. These values always were between the two measured values at the validation site. A second Kestrel weather sensor (model 4500) was compared against the first Kestrel, and had similar RH differences with the QUESTemp ${ }^{\circ}$ 32 instrumentation.

A single-layer cloud observation (amount and predominant type) was recorded along with the measured WBGT values and the required HEAT meteorological inputs. Although the S82 model accepts cloud amount and type in three layers, only a single-layer input is allowed within HEAT. This is to simplify the entry for non-meteorologists in a tactical environment. To investigate the potential error in the 
predicted WBGT due to the simplified single-cloud input, WBGT values were computed for partial and overcast single-layer and three-layer cloud conditions. Single- and three-layer results were determined for $50 \%, 80 \%, 90 \%$, and $100 \%$ cloud cover. Assigned cloud types were stratus (low), altocumulus/altostratus (middle), and thick cirrus. Results were computed for both a hot $\left(37.8^{\circ} \mathrm{C}\right.$ or $\left.100^{\circ} \mathrm{F}\right)$ and relatively dry $(25 \%$ $\mathrm{RH})$ as well as a hot $\left(32.2^{\circ} \mathrm{C}\right.$ or $\left.90^{\circ} \mathrm{F}\right)$ and humid $(50 \%$ $\mathrm{RH}$ ) environment at various solar angles (to include a solar elevation of $90^{\circ}$ ). WBGT values differed by only $0.1-0.3^{\circ} \mathrm{C}$ for the $50 \%$ cloud cover condition, with differences of more than $1.1^{\circ} \mathrm{C}$ noted only for the $90 \%$ cloud cover and overcast conditions (max difference of $1.3^{\circ} \mathrm{C}$ ). This indicates that, except for overcast or nearly overcast conditions, the error in the computed WBGT value due to the single-cloud restriction will result in a predicted heat category (Table 1) that is most likely within \pm 1 of the actual value. The worst case scenario-overcast or nearly overcast in the lowest layer while in actuality it was overcast or nearly overcast in all three layers - may result in a predicted heat category being off by possibly 2 categories. Note that the single-layer cloud input will result in a prediction of a heat category that is conservative (i.e., will error on the side of caution).

\section{b. Location, dates, and weather}

Measurements from the QUESTemp ${ }^{\circ} 32$ and Kestrel instruments were obtained at a single, highelevation rural desert site $[\sim 1250-\mathrm{m}$ above mean sea level (MSL)] in southern New Mexico (Fig. 7). Ground surface albedo, required as an irradiance model input, was assigned the value of 0.3 , corresponding to the "desert" surface type from Sellers (1965). A total of 239 observations were made during the period 27 May-9 September 2012 between midmorning and early evening. Same-day observations were approximately an hour apart. Through early July the weather conditions generally were hot and dry with clear skies and occasionally breezy conditions. After this initial period, there was the usual transition to the Desert Southwest summer monsoon environment with a generally southeasterly wind at the surface and lower levels of the atmosphere. The low-level wind direction transported increased levels of moisture from the Gulf of Mexico, resulting in increasingly humid days with dewpoint temperatures $>10^{\circ} \mathrm{C}$. Clear morning skies typically would transition to partly to mostly cloudy conditions with convective clouds and occasional

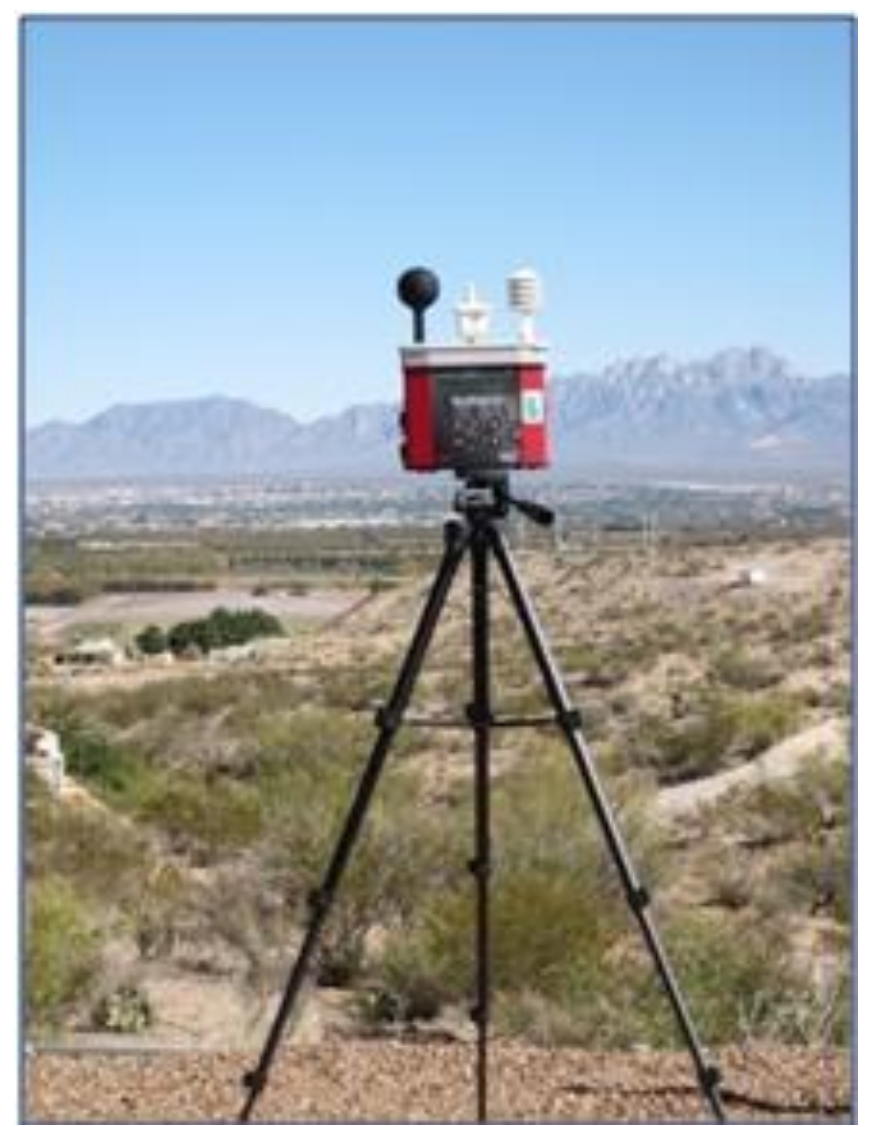

Figure 7. WBGT instrumentation at the observation site.

shower activity by late afternoon or early evening. Because the QUESTemp 32 instrument was not designed to be exposed to rain, there were no measurements during which precipitation was occurring. However, a number of measurements were made immediately after a shower or thunderstorm. This provided a limited number of observations within a relatively humid (dewpoint $\left.>15^{\circ} \mathrm{C}\right)$ and warm $\left(T_{a}\right.$ $>26^{\circ} \mathrm{C}$ ) regime.

\section{Analysis and discussion \\ a. Solar irradiance predictions}

The S82 model was used to compute the horizontal global irradiance value (as opposed to the L08 study in which irradiance was measured directly). Because the computed WBGT value is a function of the solar irradiance, it is imperative that it be modeled accurately. S82's model was developed using data from a total of 13 solar radiation measuring stations within the continental United States in the late 1970s. Eleven independent stations (also within the continental United States) were used as test sites in the 
statistical analysis of the model. Results were evaluated as functions of fractional cloud cover, solar zenith angle, the number and distribution of cloud layers present, and weather conditions. S82 reported that for the test sites the overall bias was essentially zero.

To determine the applicability of this model for use in computing the WBGT value in the HEAT application, global horizontal irradiance values were computed and compared to over 30 observations from the National Renewable Energy Laboratory (NREL) Solar Radiation Research Laboratory's Baseline Measurement System (BMS) site just east of Denver, Colorado. The observations are 60-s averaged values from instantaneous samples taken every $3 \mathrm{~s}$. Although there are a total of over 30 NREL measurement sites throughout the continental United States, Hawaii, and the United States Virgin Islands, the single BMS site was chosen because of (i) accuracy concerns at some of the other locations as well as (ii) a recommendation from an NREL Senior Scientist (A. Andreas 2013, personal communication). The BMS site instrumentation is maintained five times a week and calibrated annually. In addition, the cloud cover amount and surface albedo are available for the site. A total of 31 observations from this site were compared to the S82 model predictions (for clear sky conditions only because the cloud type was not available). A wide range of daylight times and surface albedos (0.06096), including a number of observations with snow cover, were represented. As no dependence on albedo was discernible, the model should be valid for a variety of vegetative, terrain, and surface types. Overall, 26 of the 31 modeled values underpredicted the observations, producing an overall bias (modeled observed) of $-2.4 \%$. This underprediction is to be expected as the elevation of the BMS site is over 1800 $\mathrm{m}$ MSL while the vast majority of S82's development stations were $<300 \mathrm{~m}$ MSL. For a given date, time, and location, a higher elevation would produce a higher solar irradiance because there is less of the atmosphere to attenuate incoming radiance. To investigate this, the station surface irradiation bias (modeled - observed) versus elevation and a best-fit linear regression line were plotted (Fig. 8). The correlation coefficient was -0.66 (i.e., the larger the bias, the lower the elevation). A negative bias indicates the modeled value was less than the observed value. The regression equation (not shown) suggests a $4.4 \%$ underprediction of the irradiance value for the NREL BMS site. Accounting for this expected underprediction and the actual

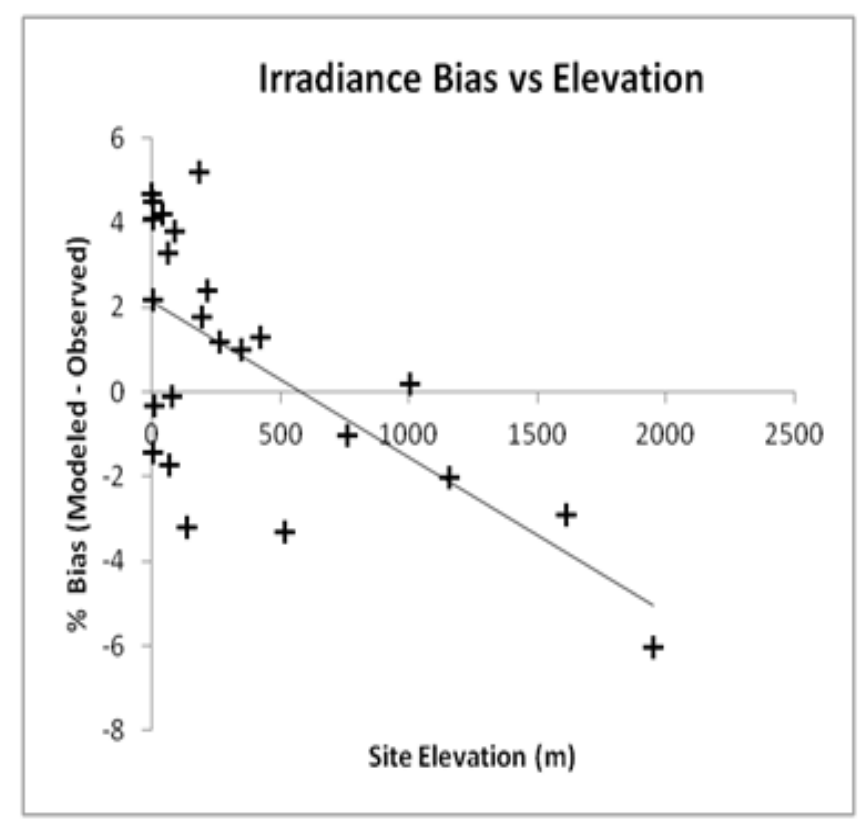

Figure 8. Plot of the Shapiro (1982) irradiance bias (modeled observed) versus site elevation (m).

underprediction (2.4\%), the S82 model results, as implemented in the HEAT application, are judged to be an acceptable representation of actual values. However, owing to the somewhat low amount of variance $(43.5 \%)$ explained by the regression equation (note the outliers about the best fit line in Fig. 8, particularly at elevations below $\sim 500 \mathrm{~m}$ MSL), it was decided to not include an irradiance adjustment in the S82 model results. At least one likely factor contributing to the remaining variance is the lack of surface visibility as an input parameter in the S82 model. Smoke and/or fog as a visibility restriction constitutes a special case in the model, but only as a yes/no condition.

\section{b. WBGT algorithm}

J. C. Liljegren (2012, personal communication) provided a file of model inputs and expected outputs to assist in the verification of the model implementation in the Java environment. Wind speed, solar irradiation, pressure, $\mathrm{RH}$, and temperature inputs were included for each of 98 entries, along with corresponding computed $T_{g}$ and $T_{w}$ output values as well as the derived WBGT. The vast majority of cases agreed to at least the fourth decimal place $\left({ }^{\circ} \mathrm{C}\right)$ for both $T_{g}$ and $T_{w}$, with the worst cases difference agreeing to the second decimal place. Given these results it was concluded that the Java version provides an accurate implementation of the ANL C-language model. 


\section{c. Model versus measurements}

The WBGT was computed for the experimental site using a total of 239 measurements of the $T_{a}, \mathrm{RH}$, wind speed, and cloud amount/type. Statistical results of the modeled versus observed values are shown in Figs. 9-11. The diagonal line from lower left to upper right represents a perfect fit between modeled and observed results. The solid diamonds (center right of the WBGT, $T_{g}$, and $T_{w}$ plots) represent a partial cloud condition in which the sun was obscured by cloud. Upon initial inspection, it would appear that these partial-cloud sun-obscured (PCSO) conditions indicate an overprediction of the WBGT value, and in some cases, a significant overprediction. However, the solar irradiation value from the S82 model represents a composite of numerous measurements for each cloud condition (e.g., 20\% cumulus sky cover) for which the sun is or is not obscured (but not recorded as part of the observation). For low cloud fractions it is likely that the majority of the measurement cases for the S82 development sites will be representative of the sun being unobscured. Therefore, it is expected that the solar irradiation value from the $\mathrm{S} 82$ model will be higher than an observed value under a PCSO measurement condition because the observed PCSO direct solar radiance component will be smaller (true even for mostly cloudy conditions although to a lesser extent). This, in turn, will lead to higher modeled $T_{w}$ and $T_{g}$ values (and hence WBGT). The two modeled-

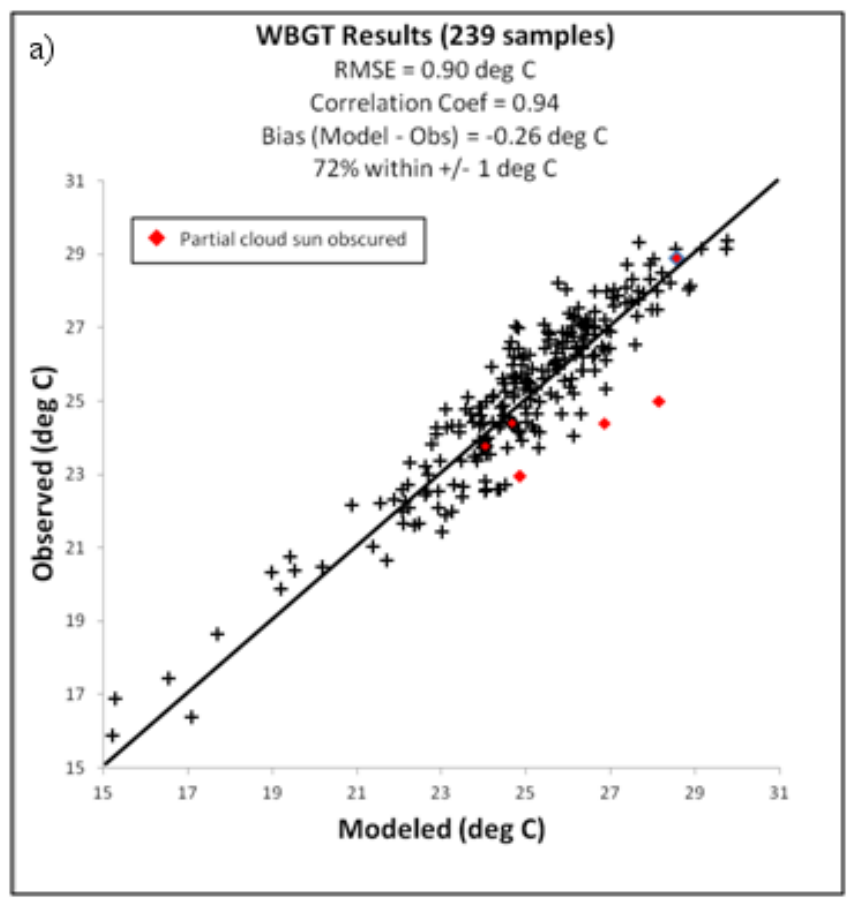

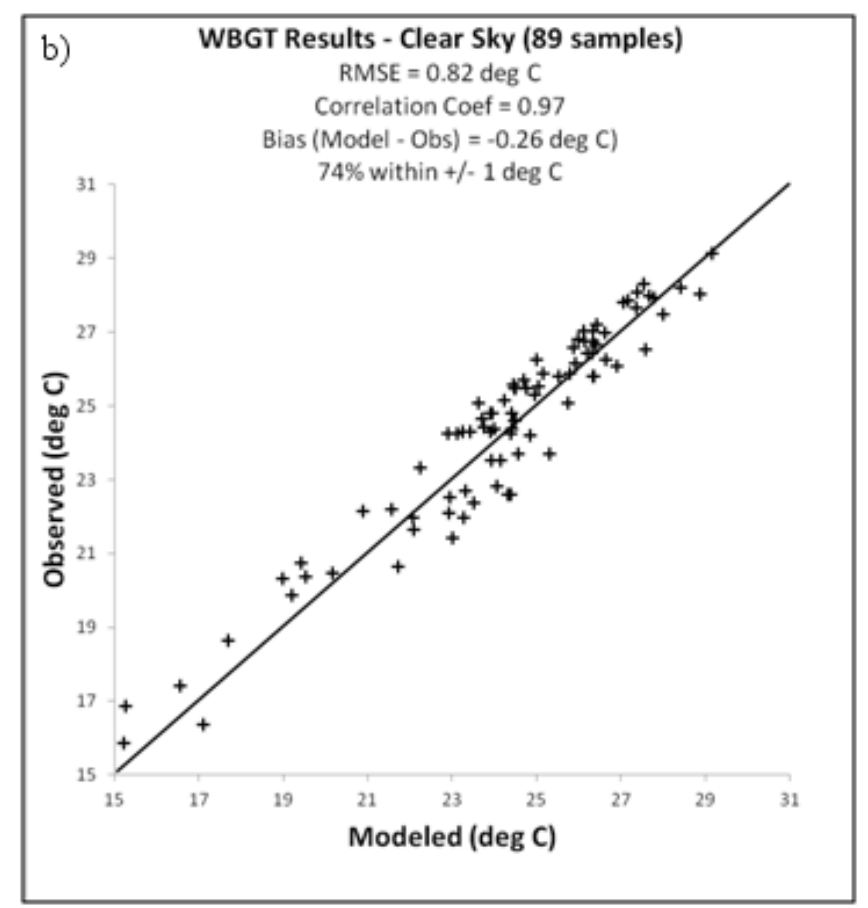

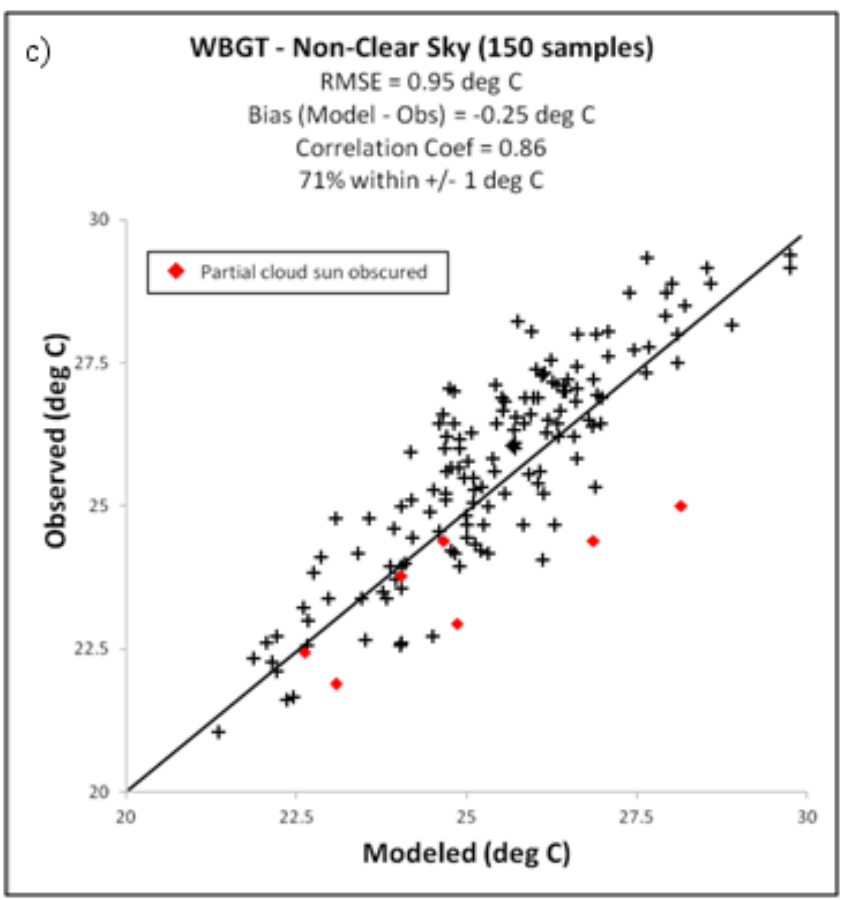

Figure 9. a) WBGT observed versus modeled values for all sky conditions. Solid red diamonds represent a partial cloud condition with the sun obscured; b) same as a) except for clear sky conditions and without the red diamonds; c) same as a) except for non-clear sky conditions.

observed $T_{g}$ differences $>10^{\circ} \mathrm{C}$ (Fig. $10 \mathrm{c}$ ) are for cloud fractions of $20 \%$ and $30 \%$. It should be noted that, for PCSO conditions, the S82 value better represents the solar load on personnel over the extended 
Table 3. Liljegren et al. (2008) and Sauter (2012) WBGT, $T_{g}$, and $T_{w}$ statistical comparisons. Liljegren et al. (2008) values show ranges as their study encompassed eight separate sites. RMSE = root mean square error; bias = modeled - observed.

\begin{tabular}{|c|c|c|c|c|c|c|c|c|}
\hline Author & Total obs. & $\begin{array}{c}\text { WBGT } \\
\text { RMSE }\left({ }^{\circ} \mathbf{C}\right)\end{array}$ & $\begin{array}{c}\text { WBGT } \\
\text { bias }\left({ }^{\circ} \mathbf{C}\right)\end{array}$ & $\begin{array}{c}\text { \% WBGT } \\
\text { within } \pm \mathbf{1}^{\circ} \mathbf{C}\end{array}$ & $\begin{array}{c}\boldsymbol{T}_{g} \text { RMSE } \\
\left({ }^{\circ} \mathbf{C}\right)\end{array}$ & $\boldsymbol{T}_{g}$ bias $\left({ }^{\circ} \mathbf{C}\right)$ & $\begin{array}{c}\boldsymbol{T}_{w} \text { RMSE } \\
\left({ }^{\circ} \mathbf{C}\right)\end{array}$ & $\boldsymbol{T}_{w}$ bias $\left({ }^{\circ} \mathbf{C}\right)$ \\
\hline Liljegren & 907 & $0.38-0.90$ & -0.73 to 0.31 & $76-100$ & $0.90-1.76$ & -0.79 to 0.64 & $0.32-1.18$ & -1.08 to 0.10 \\
\hline Sauter & 239 & 0.90 & -0.26 & 72 & 2.63 & 1.04 & 0.66 & -0.61 \\
\hline
\end{tabular}

period (tens of minutes, or even hours) over which heat stress injuries likely would be sustained. Conversely, an underprediction of $T_{w}$ and $T_{g}$ would be expected for mostly cloudy conditions in which the sun was not obscured. For overcast and clear conditions there is no ambiguity regarding solar obscurations; thus, measured and modeled $T_{w}$ and $T_{g}$ values theoretically would be expected to display less bias.

From the scatterplots (Figs. 9-11) and Table 3 it is seen that there are small negative biases in the WBGT and $T_{w}$ predictions while the $T_{g}$ has a larger magnitude positive bias. The bias, root mean square error (RMSE), and percent of modeled versus observed WBGT values within $\pm 1^{\circ} \mathrm{C}$ of each other for all sky conditions (Fig. 9a) are in general agreement with the range of values computed by L08 for the eight sites that their study included (Table 3 ).

Interestingly, there is a noticeable positive bias in the modeled $T_{g}$ values (Figs. 10a-c). Based on the prior discussion related to the S82 model versus site elevation, it would be expected that the modeled solar irradiance would be slightly underpredicted for the validation site (>1200 m MSL in elevation), resulting

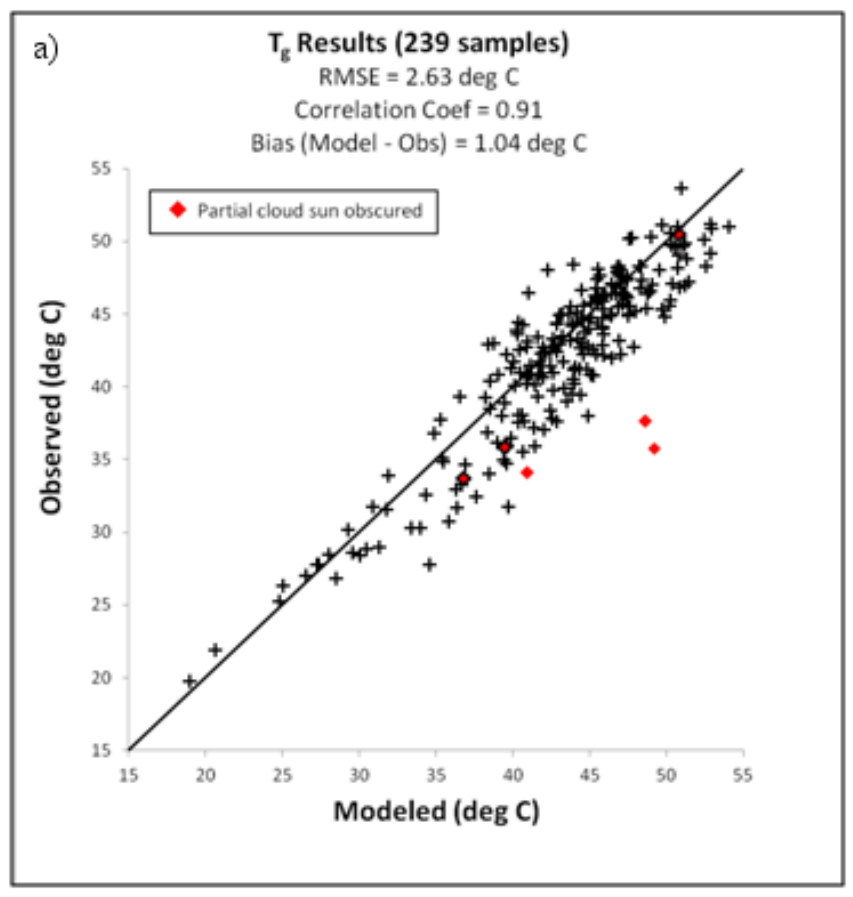

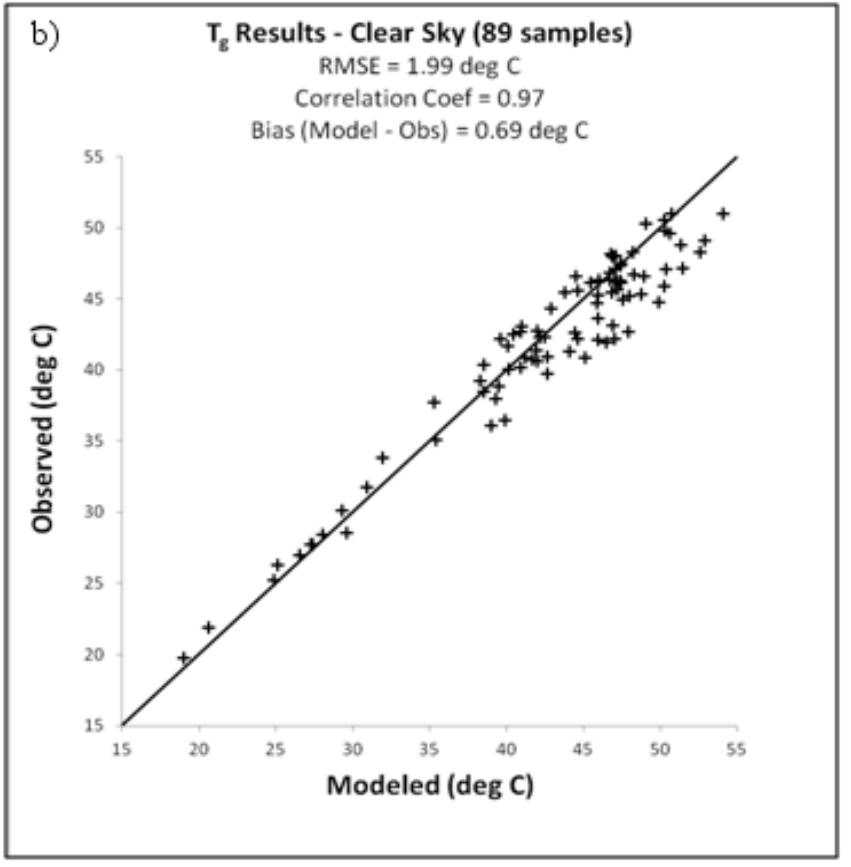

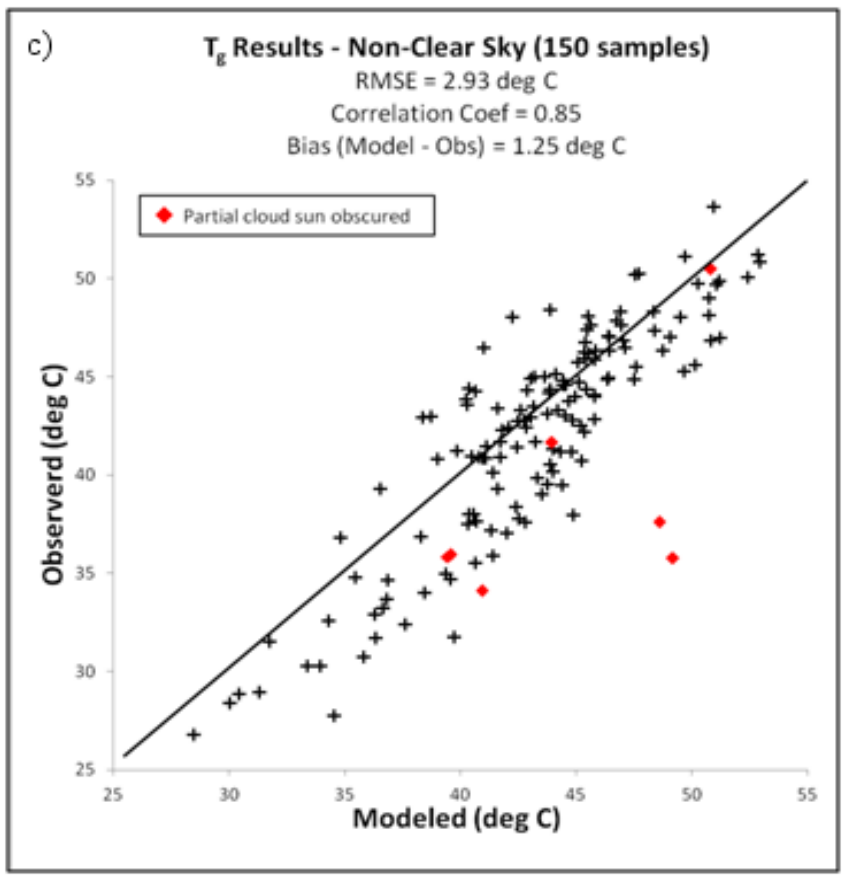

Figure 10. a) $T_{g}$ observed versus modeled for all sky conditions. Solid red diamonds represent a partial cloud condition with the sun obscured. b) same as a) except for clear sky conditions and without the red diamonds; c) same as a) except for non-clear sky conditions. 


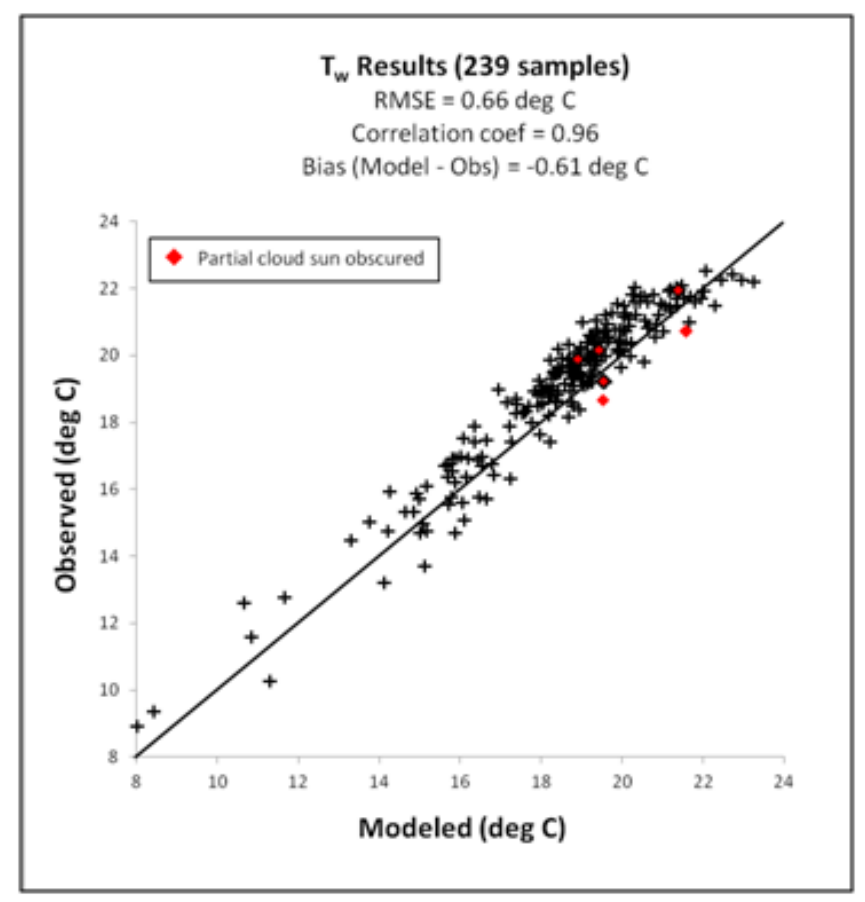

Figure 11. Natural Tw observed versus modeled for all sky conditions. Solid diamonds represent a partial cloud condition with the sun obscured.

in a negative bias for the $T_{g}$ prediction. Contributing factors to the positive $T_{g}$ bias likely are related to uncertainties in the assigned albedo, the measured $T_{g}$ value, and the underlying model.

L08 conjectured that a possible cause of the $T_{w}$ negative bias may be due to water in the $T_{w}$ reservoir that becomes heated throughout the day from solar radiance, and thus it becomes warmer than $T_{a}$. This could lead to an elevated measurement of $T_{w}$. For the current study, the vast majority of $T_{w}$ observations were for instances in which the reservoir was exposed to the direct sun, and over $80 \%$ of these observations were higher than the modeled results. It is noted that the three largest average ANL $T_{w}$ biases were for (i) Deseret Chemical Depot, Utah, (ii) Pueblo, Colorado, and (iii) Umatilla, Oregon. These sites have similar summer climates as southern New Mexico (i.e., typically sunny with low RH that contributes to overall high irradiance levels during the day). Two of these three sites also are at relatively high elevations (Deseret $1500 \mathrm{~m}$ MSL and Pueblo $1400 \mathrm{~m}$ MSL). If there is credence to the hypothesis of the solar radiance contributing to the bias, the modeled $T_{w}$ may be more representative than the observed value under these conditions.

\section{Summary and conclusions}

An ANL model based on fundamental heat and mass transfer principles to predict the WBGT value has been implemented and validated on an Androidbased mobile computing device. The ANL model requires simple meteorological inputs that are readily available in tactical military environments, with the exception of the solar irradiance value that is determined via a predictive model developed by S82. Clear sky predictions of irradiance by the S82 model compare favorably to measurements from the NREL BMS over a wide range of surface albedos.

An experimental study to compare measured versus modeled WBGT as obtained on the mobile device indicated acceptable results with over $70 \%$ of the measured/modeled WBGT values within $\pm 1^{\circ} \mathrm{C}$ of each other. These results were consistent over a wide range of relative humidities (6-69\%), temperatures $\left(20-38^{\circ} \mathrm{C}\right)$, wind speeds $\left(1-8 \mathrm{~m} \mathrm{~s}^{-1}\right)$, and cloud cover (clear-overcast). Thus, the mobile application is capable of successfully determining the WBGT heat stress category required to provide specific heat stress guidance to soldiers for a variety of environmental conditions. In partly cloudy conditions, the HEAT may well provide a more representative WBGT value than an instantaneous value from a tactical WBGT instrument.

An accurate WBGT model, in conjunction with modeled solar irradiance, has distinct advantages over WBGT instrumentation in terms of expense, maintenance, convenience, and logistics-especially in a tactical military environment. Consider, for example, an excerpt from Appendix B of TB MED 507 detailing the natural wet-bulb measurement methodology: "It is not acceptable to depend upon capillary action to completely wet the wick. The wick should be wetted by direct application of water from a syringe $\sim 1 / 2$ hour before each reading. The wick should be clean and new wicks should be washed before using; in addition, flask water should be changed daily." Similarly, regarding the globe temperature measurement, Appendix B notes that "The globe must be kept dull black at all times, free of dust or rain streaks, by dusting, washing, or repairing if necessary. The globe thermometer should be exposed at least 25 minutes before it is read."

The HEAT application, incorporating the WBGT model, readily allows a "what if" scenario to be 
addressed in which heat stress impacts for future times and meteorological conditions can be quickly ascertained. This capability is not available via use of the tactical WBGT kit (or any WBGT instrumentation) and provides an advantage in mission planning.

Although it would have been desirable to obtain validation results for other locations, the L08 WBGT model results (as implemented in HEAT) cover a diverse range of geographic and meteorological environments, from higher altitude desert locales (Pueblo, Colorado, and Tooele, Utah) to relatively low elevation (< 210 m MSL), humid locales (Pine Bluff, Arkansas, and Anniston, Alabama). For all of the ANL sites, WBGT bias was $\leq 0.4^{\circ} \mathrm{C}$, RMSE was $<0.6^{\circ} \mathrm{C}$, and $>90 \%$ of predictions were within $1^{\circ} \mathrm{C}$ of measured values.

Handheld Kestrel weather sensors are currently in use by military personnel (Fig. 1), and Android-based smartphones are becoming prevalent. It is anticipated that the HEAT application will be submitted to the Defense Information Systems Agency's Mobile Application Store in 2014.

HEAT has applicability not only in the military environment but also for civilians (e.g., emergency response and planning). HEAT has been tested on both Android-based smartphones and tablets. An evaluation of HEAT by a United States Special Operations Command Technical Experimentation Team noted that "The system is very easy to learn, simple to use, and presents the information intelligently." They also stated that "The form factor, smartphone app, would definitely be of value to units...."

Acknowledgments. The author thanks (i) Dr. James Liljegren and his coauthors from ANL for providing the Clanguage software and verification data for the WBGT model used in this study, as well as (ii) Afshin Andreas of NREL for his insight regarding solar-measurement site considerations.

\section{REFERENCES}

3M, cited 2013: QUESTemp 32 User Manual. 3M Personal Safety Division, $18 \mathrm{pp}$. [Available online at multimedia $.3 \mathrm{~m} . \mathrm{com} / \mathrm{mws} / \mathrm{mediawebserver}$ ?mwsId=66666UgxGCu NyXTtOxf6oxT6EVtQEcuZgVs6EVs6E666666-\&fn=QT32UM_web_rev.g.pdf.]

Carter R., III, S. N. Cheuvront, J. O. Williams, M. A. Kolka, L. A. Stephenson, M. N. Sawka, and P. J. Amoroso, 2005: Epidemiology of hospitalizations and deaths from heat illness in soldiers. Med. Sci. Sports Exerc., 37 (8), 1338-1344.

Department of the Army and Air Force Headquarters, 2003: Heat stress control and heat casualty management. Technical Bulletin Medical 507, Air Force Pamphlet 48-152 (I), 72 pp. [Available online at armypubs.army. mil/med/DR_pubs/dr_a/pdf/tbmed507.pdf.]

Liljegren J. C., R. A. Carhart, P. Lawday, S. Tschopp, and R. Sharp: 2008: Modeling the wet bulb globe temperature using standard meteorological measurements. $J$. Occup. Environ. Hyg., 5, 645-655.

NCDC, 1978: SOLMET Volume 1-Users Manual, TD9724, Hourly solar radiation-surface meteorological observations. National Climatic Data Center, NOAA, U.S. Department of Commerce, 98 pp. , 1979: SOLMET Volume 2-Final Report, TD-9724, Hourly solar radiation-surface meteorological observations. National Climate Data Center, NOAA, U.S. Department of Commerce, $184 \mathrm{pp}$.

Sauter, D., 2012: Hot Environment Assessment Tool (HEAT) User's Guide. Army Research Laboratory Report, ARL-MR-0809, 16 pp. [Available online at www.arl.army.mil/arlreports/2012/ARL-MR-0809.pdf.]

Sellers, W. D., 1965: Physical Climatology, University of Chicago Press, 272 pp.

Shapiro, R., 1982: Solar radiative flux calculations from standard surface meteorological observations. Air Force Geophysics Laboratory Scientific Report No. 1, AFGLTR-82-0039, 55 pp. [Available online at www.dtic.mil/ dtic/tr/fulltext/u2/a118775.pdf.] 